\title{
Numerical Investigation on the Hydrogen-Assisted Start-Up of Methane-Fueled, Catalytic Microreactors
}

\author{
Symeon Karagiannidis • John Mantzaras
}

Received: 25 August 2010 / Accepted: 28 February 2011 / Published online: 24 March 2011

(C) Springer Science+Business Media B.V. 2011

\begin{abstract}
The hydrogen-assisted start-up of methane-fueled, catalytic microreactors has been investigated numerically in a plane-channel configuration. Transient 2$\mathrm{D}$ simulations have been performed in a platinum-coated microchannel made of either ceramic or metallic walls. Axial heat conduction in the solid wall and surface radiation heat transfer were accounted for. Simulations were performed by varying the inlet pressure, the solid wall thermal conductivity and heat capacity, and comparisons were made between fuel mixtures comprising $100 \% \mathrm{CH}_{4}$ and $90 \% \mathrm{CH}_{4}-$ $10 \% \mathrm{H}_{2}$ by volume. A significant reduction in the ignition $\left(t_{\mathrm{ig}}\right)$ and steady-state $\left(t_{\mathrm{st}}\right)$ times was evident for microreactors fed with hydrogen-containing mixtures in comparison to pure methane-fueled ones, for all pressures and reactor materials investigated, with hydrogen having a direct thermal rather than chemical impact on catalytic microreactor ignition. The positive impact of $\mathrm{H}_{2}$ addition was attenuated as the pressure (and the associated $\mathrm{CH}_{4}$ catalytic reactivity) increased. Reactors with low wall thermal conductivity (cordierite material) benefited more from hydrogen addition in the fuel stream and exhibited shorter ignition times compared to higher thermal conductivity ones ( $\mathrm{FeCr}$ alloy) due to the creation of spatially localized hot spots that promoted catalytic ignition. At the same time, the cordierite material required shorter times to reach steady state. Microreactor emissions were impacted positively by the addition of hydrogen in the fuel stream, with a significant reduction in the cumulative methane emissions and no hydrogen breakthrough. Finally, gasphase chemistry was found to elongate the steady-state times for both ceramic and metallic materials.
\end{abstract}

Keywords Catalytic microreactors - Transient simulation · Hetero-/homogeneous combustion $\cdot$ Hydrogen-assisted combustion

S. Karagiannidis · J. Mantzaras ( $\varangle)$

Combustion Research, Paul Scherrer Institute (PSI),

$\mathrm{CH}-5232$ Villigen, Switzerland

e-mail: ioannis.mantzaras@psi.ch 


\section{Introduction}

In recent years, hydrocarbon-fueled catalytic microreactors have been the focus of intense research efforts [1], as they can reliably supply the necessary thermal power for a variety of portable power generation systems with demonstrated energy densities considerably higher than those obtained with state-of-the-art Li-ion batteries [2]. Catalytic microburners have thus been investigated for use in scaled-down devices employing conventional thermal cycles, with applications ranging from micro-Stirling engines [2] to direct chemical-to-thermal energy conversion devices [3].

With most of the experimental work on catalytic microreactors focusing on operational aspects such as fuel conversion and thermal management [4], a wide range of computational models of varying complexity are increasingly being employed to provide insight on the physics of microscale catalytic combustion. Such approaches include simplified 1-D models with lumped heat and mass transport coefficients investigating the performance of propane-fueled microreactors [5], 2-D models with detailed surface chemistry without heat conduction in the solid wall probing the robustness of methane-fueled microreactors against external heat losses [6] and finally full 2-D CFD models whereby all relevant heat transfer mechanisms in the solid (heat conduction and surface radiation heat transfer) along with detailed catalytic and gas-phase chemistries are accounted for [7].

The start-up of microreactors, and catalytic microburners in particular, is of prime importance in small-scale power generation devices; for example, long heatup times can reduce the availability of the microdevice over extended periods and also result in substantial pollutant emissions. While the aforementioned numerical studies delineated the steady-state performance of catalytic microreactors, only a few investigations focused on their transient behavior, with particular emphasis on the ignition process (light-off). Such works include the mapping of hydrogen/air flame dynamics in catalytic and non-catalytic microchannels having prescribed wall temperatures using a fully transient 2-D CFD code [8], as well as investigations of optimum ignition strategies in a propane-fueled catalytic microreactor using a 1-D transient code [9].

Since fully transient simulations for reacting flows can be computationally demanding, a number of simplifications have been introduced for catalytic combustion applications allowing extensive parametric numerical investigations. One such simplified computational model used widely for conventional-sized honeycomb reactors involves a "continuum" description of the entire reactor structure and invokes the quasisteady treatment of the gaseous phase as a result of the disparity between the gas-phase and solid-phase characteristic time scales [10]. In a recent combined experimental and numerical study [11], the light-off and extinction in the catalytic partial oxidation (CPO) of methane over rhodium were investigated by invoking the quasisteady assumption for the gas to model the 2-D reacting flow in a single catalytic channel. The validated transient computational model was subsequently used to study ignition characteristics in a methane-fueled, catalytic microreactor channel [12]. Therein, detailed hetero-/homogeneous chemistry was employed along with all relevant heat transfer mechanisms in the reactor, with emphasis on the impact of solid heat conduction and thermal radiation heat transfer from the catalytic walls on microreactor ignition and attainment of steady state. Parametric studies were carried out to identify the effect of various operational parameters such as pressure, fuel/air equivalence ratio, solid material properties and radiation properties on the transient 
processes leading to ignition and finally to steady-state. Operation at higher-thanatmospheric pressures was identified as particularly favorable due to a subsequent significant reduction in the times required for microreactor ignition and attainment of steady state.

In the present work, a numerical study is undertaken to investigate the start-up of methane-fueled, catalytic microreactors using methane/hydrogen fuel blends, as an alternative strategy for rapid light-off. A full elliptic, transient in the solid and quasisteady in the gas numerical code is used to simulate the reacting flow in a catalytic plane channel configuration with a gap of $1 \mathrm{~mm}$ and a length of $10 \mathrm{~mm}$, with this setup effectively representing a single channel of a catalytic honeycomb microburner structure. Detailed catalytic and gas-phase reaction mechanisms for the total oxidation of methane and hydrogen on platinum have been used. The investigation is focused on operating conditions pertinent to microturbine-based microreactor systems [13-15], which include preheated fuel/air mixtures and inlet pressures up to 5 bar. The main objective is to quantify the impact of hydrogenassisted hetero-/homogeneous combustion on the elapsed time required for microreactor ignition and subsequent attainment of steady state. Operating pressures in the range of 1 bar $\leq p \leq 5$ bar are investigated for two representative microreactor materials, namely cordierite ceramic and $\mathrm{FeCr}$ alloy metal. Comparisons are made with the start-up times of catalytic microreactors operating with pure methane/air streams (no hydrogen addition [12]); moreover, the effect of hydrogen-assisted catalytic combustion on microreactor emissions is assessed. It is noted that this work presents for the first time transient results on the hydrogen-assisted hetero-/ homogeneous combustion of methane in catalytic microreactors at higher-thanatmospheric pressures and for different microreactor wall materials.

The current article is organized as follows. The numerical model is presented first. Hydrogen-assisted catalytic combustion is qualitatively assessed next, followed by results on the impact of hydrogen addition in the fuel/air stream on microreactor ignition and steady-state times, at various pressures and for both solid materials investigated. Catalytic microreactor start-up characteristics during operation with methane/hydrogen fuel blends are subsequently analyzed, followed by an assessment of pollutant emissions during the microreactor start-up process. Finally, the impact of gas-phase chemistry is discussed.

\section{Numerical Model}

A full-elliptic, two-dimensional CFD code [11, 16] has been used to simulate the flow domain in a plane channel having length $L=10 \mathrm{~mm}$, height $2 b=$ $1 \mathrm{~mm}$ and wall thickness $\delta=50 \mu \mathrm{m}$ (see Fig. 1). The initial $1 \mathrm{~mm}$ channel length was catalytically inert, while the remaining $L_{a}=9 \mathrm{~mm}$ was coated with platinum. Due to symmetry, only half of the channel domain was modeled. The global fuelto-air equivalence ratio of the examined $\mathrm{CH}_{4} / \mathrm{H}_{2} /$ air mixtures was $\varphi=0.37$, which was obtained when substituting $10 \% \mathrm{CH}_{4}$ by volume with $\mathrm{H}_{2}$ in an initial lean $\mathrm{CH}_{4}$ /air stream of equivalence ratio $\varphi=0.40$. The inlet temperature was set to $T_{\mathrm{IN}}=$ $850 \mathrm{~K}$, a value practically achievable in recuperated microreactor thermal cycles [13]. The initial temperature for the channel solid wall was uniform and equal to the incoming mixture temperature, such that $T_{\mathrm{W}}(x, t=0)=850 \mathrm{~K}$. Calculations were 
Fig. 1 Schematic of the catalytic microreactor configuration

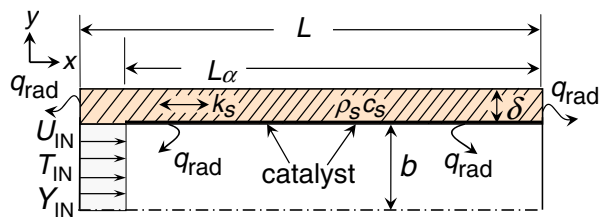

performed for pressures $p=1,2,3,4$ and 5 bar, while the nominal inlet velocity was $U_{\mathrm{IN}}=1.5 \mathrm{~m} / \mathrm{s}$ at $p=1$ bar, a value typical for microreactors. When increasing the inlet pressure, the inlet velocity was decreased accordingly, so as to maintain the same mass throughput $\left(\rho_{\mathrm{IN}} U_{\mathrm{IN}}\right)$. Two types of solid materials were examined for the microreactor wall, cordierite ceramic with a thermal conductivity of $k_{\mathrm{s}}=2 \mathrm{~W} / \mathrm{mK}$ and a thermal capacity of $\rho_{\mathrm{s}} c_{\mathrm{s}}=3806 \mathrm{~kJ} / \mathrm{m}^{3} \mathrm{~K}$ and $\mathrm{FeCr}$ alloy metal with $k_{\mathrm{s}}=16 \mathrm{~W} / \mathrm{mK}$ and $\rho_{\mathrm{s}} c_{\mathrm{s}}=4428 \mathrm{~kJ} / \mathrm{m}^{3} \mathrm{~K}$.

The quasisteady assumption requires that the convective and diffusive time scales of the gas are appreciably shorter than the characteristic time scales for diffusion of heat in the solid, thus allowing the gaseous flow to equilibrate to the channel solid wall temperature at any given time during the ignition event. The 2-D steady calculations of the flow field were then coupled to a 1-D transient energy balance equation for the solid. Justification for the choice of a 1-D model for the solid energy equation has been provided elsewhere [12].

The net radiation method for diffuse-gray areas $[12,17]$ accounted for radiation exchange between the discretized channel wall elements themselves, and between each wall element and the inlet and outlet channel enclosures. The inlet and outlet planes of the enclosure had emissivities equal to those of the channel wall surfaces, $\varepsilon_{\mathrm{IN}}=\varepsilon_{\text {OUT }}=\varepsilon=0.6$, while the inlet and outlet exchange temperatures were set equal to the inlet and outlet mixing cup temperatures, respectively. In the numerical model, the geometrical surface area has been considered equal to the catalytically active area. Radiative boundary conditions were finally applied to the vertical front and rear solid wall faces. It should be noted that, while the outer horizontal channel wall was treated as adiabatic, the reactor itself was non-adiabatic due to radiation heat losses towards the colder inlet enclosure.

The combustion of lean methane/hydrogen blends on platinum was modeled using the elementary heterogeneous scheme of Deutschmann et al. [18] (24 reactions, 11 surface and 9 gaseous species), coupled to the $\mathrm{C}_{1} / \mathrm{H} / \mathrm{O}$ elementary gas-phase mechanism of Warnatz et al. [19] (26 species, 108 reactions). In the catalytic mechanism, a surface site density $\Gamma=2.7 \times 10^{-9} \mathrm{~mol} / \mathrm{cm}^{2}$ was used. The catalytic mechanism has been validated against spatially-resolved measurements of major species concentrations across the boundary layer formed in a Pt-coated channel at pressures of 1 to 16 bar, while the gas-phase mechanism has been tested against $\mathrm{OH}$ laser induced fluorescence (LIF) homogeneous ignition measurements in the same channel reactor, again at pressures of 1 to 16 bar [20,21]. To reproduce homogeneous ignition at $p \leq 6$ bar (a range encompassing the present investigation), the gaseous mechanism has been modified in the single reaction $\mathrm{CHO}+\mathrm{M} \Leftrightarrow \mathrm{CO}+\mathrm{H}+\mathrm{M}$; this modification was further supported by recent kinetic measurements, as described in [21]. Mixture-average diffusion was used, with transport properties calculated from the CHEMKIN database [22]. Surface and gas-phase reaction rates were evaluated using Surface-CHEMKIN [23] and CHEMKIN, respectively [24]. 
An orthogonal staggered grid with $100 \times 24$ points in the $x$ - and $y$-direction, respectively, over the channel half-height produced a grid-independent solution for the flow domain. Finer spacing towards the channel wall and entry section was used. A 100 grid node resolution in the $x$-direction was also used to discretize the solid wall. At the inlet $(x=0)$, uniform profiles of species, temperature and axial velocity were applied, while zero-Neumann conditions were set at the outlet $(x=L)$ and plane of symmetry $(y=0)$. No-slip was applied for both velocity components at the gaswall interface $(y=b)$. The coupled gas and solid phases were solved iteratively and convergence was achieved at each time step when the solid temperature did not vary at any position along the wall by more than $10^{-5} \mathrm{~K}$.

The quasisteady approximation also entails the assumption of catalytic chemical reaction times being shorter than the heat conduction times in the solid, so as to ensure chemical equilibration at the local wall temperature during an integration time step of the solid. Using the same methodology as in [12], a time step $\Delta t=$ $50 \mathrm{~ms}$ was subsequently used in this work, having a value sufficiently longer than the chemical time scales present during catalytic microreactor ignition.

\section{Results and Discussion}

Transient simulations were performed in order to assess the impact of hydrogen addition in methane-fueled catalytic microreactors during the start-up phase. First, hydrogen-assisted heterogeneous combustion is assessed in an ideal catalytic reactor, which indicates the potential benefit of substituting part of methane in the fuel/air stream with hydrogen. Next, full 2-D simulations are performed to quantify the effect of hydrogen addition in methane-fueled microreactor start-up times. Operating parameters of interest in this case are the inlet pressure $p$, the microreactor wall material, and finally the potential impact of gas-phase reactions. The computed characteristic times of interest (describing the microreactor start-up process) are the ignition time $\left(t_{\mathrm{ig}}\right)$, defined as the elapsed time required to reach $50 \%$ of fuel conversion at the channel outlet, and the steady-state time $\left(t_{\mathrm{st}}\right)$, defined as the elapsed time whereby the outlet gas temperature varied by less than $10^{-3} \mathrm{~K}$. By running a steady-state version of the code, it was confirmed that the adopted definition of steady state in the transient simulations reproduced the true steady-state outlet temperature within $1 \mathrm{~K}$.

\subsection{Hydrogen-assisted heterogeneous combustion}

In order to decouple the underlying chemical processes from microreactor-specific effects (e.g., thermal inertia of solid wall, flow conditions) and to acquire an initial estimate on the effect of hydrogen addition on catalytic methane combustion, computations have been carried out with an ideal reactor model. Catalytic lightoff times were computed in a constant pressure batch reactor, under conditions pertinent to the subsequent full 2-D channel simulations. To this direction, the homogeneous-reaction package SENKIN of CHEMKIN [25] has been augmented with the inclusion of catalytic reactions (model details have been provided elsewhere [11]). Calculations were performed for two fuel/air mixtures, one containing pure methane fuel $\left(100 \% \mathrm{CH}_{4}\right)$ at a fuel/air equivalence ratio of $\varphi=0.40$, and another 
containing $90 \% \mathrm{CH}_{4}$ and $10 \% \mathrm{H}_{2}$, at an overall fuel/air equivalence ratio of $\varphi=$ 0.37 . Reactor pressure for both cases was $p=1 \mathrm{bar}$, while the initial fuel/air mixture and reactor temperatures were $T=850 \mathrm{~K}$. To mimic the confinement of a catalytic microreactor channel, the surface-to-volume ratio of the ideal batch reactor was set to $S / V=20 \mathrm{~cm}^{-1}$, a value equal to the $S / V$ value of the 2-D plane channel microreactor in the ensuing calculations. Figure 2 presents the computed temporal evolution of temperature during light-off for the aforementioned fuel/air mixtures.

Keeping in line with the definition of $t_{\text {ig }}$ in Section 3, it is evident from the top graph in Fig. 2 that, despite the overall lower equivalence ratio (and also lower chemical energy input), the $\mathrm{CH}_{4} / \mathrm{H}_{2}$ blend achieves catalytic light-off appreciably faster than the pure methane case. In the case of the $\mathrm{CH}_{4} / \mathrm{H}_{2}$ blend, the initial reactor temperature of $850 \mathrm{~K}$ is high enough to rapidly consume all of $\mathrm{H}_{2}$ (see Fig. 2, bottom graph); this in turn leads to a temperature rise (evident during the first $3 \mathrm{~ms}$ in Fig. 2), which further promotes methane catalytic reactions and results in faster light-off. It is thus expected that even a $10 \%$ substitution of $\mathrm{CH}_{4}$ with $\mathrm{H}_{2}$ in the subsequent microreactor simulations can significantly impact the computed ignition and steadystate times; moreover, pollutant emissions (namely unburned $\mathrm{CH}_{4}$ ) are also expected to be affected, partly due to the lower methane concentration in the $\mathrm{CH}_{4} / \mathrm{H}_{2}$ blends and partly due to the faster light-off (since most of the cumulative reactor emissions are attributable to the pre-ignition start-up phase [12]).

\subsection{Ignition and steady-state times for $\mathrm{CH}_{4} / \mathrm{H}_{2}$-fueled catalytic microreactors}

Computed ignition $\left(t_{\mathrm{ig}}\right)$ and steady-state $\left(t_{\mathrm{st}}\right)$ times for all cases considered in this study are provided in Table 1 . The fuel/air equivalence ratio is kept constant at $\varphi=$ 0.37 for all cases, with a constant ratio of $90 \% \mathrm{CH}_{4}-10 \% \mathrm{H}_{2}$ by volume in the fuel

Fig. 2 Temporal evolution of temperature (top graph) in an ideal batch reactor and respective temporal evolution of fuel mole fractions (bottom graph) for two fuel/air mixtures: $100 \% \mathrm{CH}_{4}$, $\varphi=0.40$ (solid line) and $90 \% \mathrm{CH}_{4}$ (dashed line)-10\% $\mathrm{H}_{2}$ (dash-dotted line), $\varphi=0.37$. Symbols denote catalytic light-off times $\left(t_{\text {ig }}\right)$

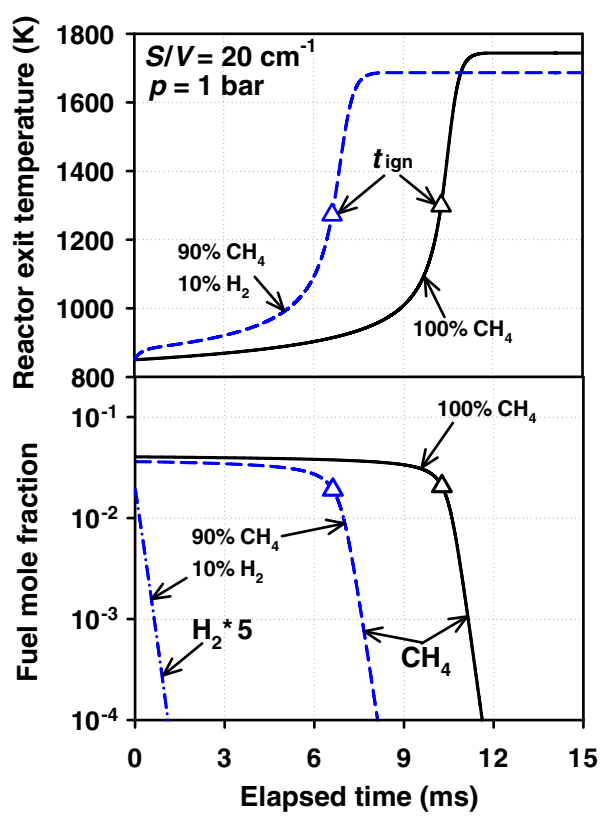


Table 1 Case number, microreactor material, inlet pressure $p$ (bar), inlet velocity $U_{\mathrm{IN}}(\mathrm{m} / \mathrm{s})$, ignition time $t_{\mathrm{ig}}(\mathrm{s})$ and steady-state time $t_{\mathrm{st}}(\mathrm{s})$

\begin{tabular}{llllll}
\hline Case & Material & $p($ bar $)$ & $U_{\text {IN }}(\mathrm{m} / \mathrm{s})$ & $t_{\text {ig }}(\mathrm{s})$ & $t_{\text {st }}(\mathrm{s})$ \\
\hline 1 & Cordierite & 1 & 1.50 & 12.9 & 27.5 \\
2 & Cordierite & 2 & 0.75 & 9.9 & 23.2 \\
3 & Cordierite & 3 & 0.50 & 9.2 & 21.5 \\
4 & Cordierite & 4 & 0.38 & 8.9 & 20.8 \\
5 & Cordierite & 5 & 0.30 & 8.7 & 20.5 \\
6 & FeCr alloy & 1 & 1.50 & 16.5 & 31.4 \\
7 & FeCr alloy & 2 & 0.75 & 13.2 & 25.7 \\
8 & FeCr alloy & 3 & 0.50 & 12.2 & 24.4 \\
9 & FeCr alloy & 4 & 0.38 & 11.7 & 23.8 \\
10 & FeCr alloy & 5 & 0.30 & 11.4 & 23.4 \\
11 & Cordierite & 1 & 1.50 & 12.1 & 27.8 \\
12 & Cordierite & 5 & 0.30 & 8.5 & 20.9 \\
13 & FeCr alloy & 1 & 1.50 & 16.2 & 32.2 \\
14 & FeCr alloy & 5 & 0.30 & 11.2 & 25.7 \\
\hline
\end{tabular}

Cases 1 to 10 pertain to simulations with surface reactions only, while Cases 11 to 14 include gasphase chemistry. In all cases $\varphi=0.37$ with $90 \% \mathrm{CH}_{4}-10 \% \mathrm{H}_{2}$ by volume

stream. As the pressure is increased from the nominal case of $p=1$ bar up to 5 bar, the inlet velocity is adjusted so that the mass throughput $\rho_{\text {IN }} U_{\text {IN }}$ remains constant.

Previous studies on the steady-state stability of methane-fueled catalytic microreactors have exemplified the impact of high pressure operation in maintaining vigorous hetero-/homogeneous combustion in microchannels, owing to the positive $p^{+0.47}$ pressure dependence of the catalytic reactivity of methane on platinum [7]. Moreover, transient simulations on the start-up of methane-fueled catalytic microreactors delineated a similar trend, in which the ignition and steady-state times during the heat-up phase of such microreactors were significantly reduced as the operating pressure was increased, thanks to the positive pressure dependence of the catalytic reactivity, even at relatively low microreactor temperatures [12]. The same trend is observed from the characteristic times presented in Table 1, and is illustrated in Figs. 3 and 4 for the hydrogen-assisted start-up of methane-fueled catalytic microreactors, where computed $t_{\mathrm{ig}}$ and $t_{\mathrm{st}}$ times are plotted for Cases 1-5

Fig. 3 Ignition $\left(t_{\mathrm{ig}}\right)$ and steady-state $\left(t_{\mathrm{st}}\right)$ times versus inlet pressure for Cases $1-5$ in Table 1. Triangles ignition times; squares steady-state times. Solid lines $90 \%$ $\mathrm{CH}_{4}-10 \% \mathrm{H}_{2}$ fuel blend $(\varphi=0.37)$; dashed lines $100 \% \mathrm{CH}_{4}$ fuel $(\varphi=0.40)$. The mass inflow $\left(\rho_{\text {IN }} U_{\text {IN }}\right)$ is constant for all cases. Cordierite microreactor

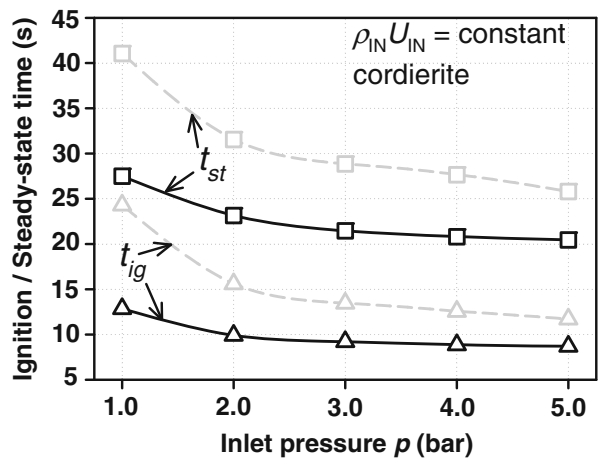


Fig. 4 Ignition $\left(t_{\text {ig }}\right)$ and steady-state $\left(t_{\mathrm{st}}\right)$ times versus inlet pressure for Cases 6-10 in Table 1. Triangles ignition times; squares steady-state times. Solid lines $90 \%$ $\mathrm{CH}_{4}-10 \% \mathrm{H}_{2}$ fuel blend $(\varphi=0.37)$; dashed lines $100 \% \mathrm{CH}_{4}$ fuel $(\varphi=0.40)$. The mass inflow $\left(\rho_{\text {IN }} U_{\text {IN }}\right)$ is constant for all cases. $\mathrm{FeCr}$ alloy microreactor

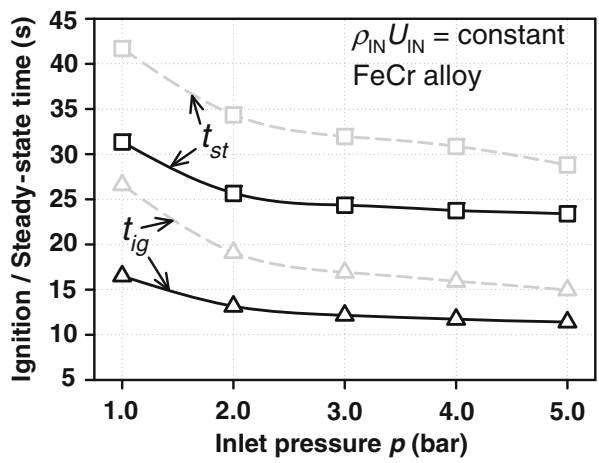

(Fig. 3) and Cases 6-10 (Fig. 4). For comparison purposes, ignition and steadystate times for the same microreactor configurations are plotted in Figs. 3 and 4 for pure methane/air mixtures, for pressures $p=1$ to 5 bar and two microreactor wall materials.

Evident from Figs. 3 and 4 is the positive effect of high operating pressure on the ignition and steady-state times of catalytic microreactors fueled with $\mathrm{CH}_{4} / \mathrm{H}_{2}$ blends, albeit with a less pronounced impact as the pressure increases beyond $p>3$ bar, for both materials studied. More pronounced, however, is the difference between characteristic times for microreactors fueled with $\mathrm{CH}_{4} / \mathrm{H}_{2}$ blends (solid curves, Figs. 3 and 4 ) and the corresponding times for pure $\mathrm{CH}_{4}$-fueled ones (dashed curves, Figs. 3 and 4 ). By replacing $10 \%$ vol. of methane with hydrogen in the fuel stream, a significant reduction in both $t_{\text {ig }}$ and $t_{\text {st }}$ can be achieved, despite the subsequent reduction in the global fuel/air equivalence ratio. More pronounced benefits are observed at lower operating pressures, especially at atmospheric pressure. Characteristically, for a cordierite catalytic microreactor operating at $p=1$ bar, replacing $10 \%$ vol. of methane with hydrogen in the fuel stream reduces the ignition and steady-state times by $\sim 47 \%$ and $\sim 33 \%$ respectively, while at $p=5$ bar the corresponding reductions are $\sim 25 \%$ and $\sim 20 \%$. In order to place the positive impact of hydrogen addition in perspective, it should be pointed out that to achieve the same reduction in $t_{\text {ig }}$ and $t_{\mathrm{st}}$ in the pure methane-fueled cases, the operating pressure would have to be increased to $p=4$ bar. As the operating pressure increases, the reduction in $t_{\text {ig }}$ and $t_{\text {st }}$ for the $\mathrm{CH}_{4} / \mathrm{H}_{2}$ blends compared to pure $\mathrm{CH}_{4}$ cases is less pronounced; the catalytic reactivity of methane on platinum at elevated pressures is high enough [20] leading to fast light-off and attainment of steady state, such that the effect of hydrogen is attenuated.

The elapsed time between light-off and steady state $\left(t_{\mathrm{st}}-t_{\mathrm{ig}}\right)$ remains relatively constant among cases with identical fuel blends, which points out to the fact that, once ignited, the chemical energy input per unit time is more important in determining how fast the microreactor will attain steady state. For $\mathrm{CH}_{4} / \mathrm{H}_{2}$ fuel blends the time required for steady state is, on average, $\sim 15 \%$ shorter compared to pure $\mathrm{CH}_{4}$ cases; this can be attributed to the fact that cases with $\mathrm{CH}_{4} / \mathrm{H}_{2}$ fuel blends suffer less thermal radiation heat losses to the channel inlet and outlet enclosures owing to their lower overall equivalence ratio and to the resulting lower surface temperatures [26]. 


\subsection{Effect of microreactor wall material}

Cordierite microreactors benefit more from hydrogen-assisted catalytic combustion than $\mathrm{FeCr}$ alloy ones. Figure 5 presents microreactor wall temperature profiles for Cases 5 and 10 in Table 1 (both at $p=5$ bar) at various time instances, including the characteristic ignition and steady-state times. In both cases, rear-end ignition is observed, which is common for all the conditions in Table 1. It will be shown in the next section that, although the wall temperature profiles indicate an overall backend ignition process, hydrogen fuel is essentially igniting at the beginning of the catalyst-coated section, leading to a pseudo-ignition seen as a slight bulging of the wall temperature profile around $x=1 \mathrm{~mm}$ (e.g. wall temperature profile at $t=8.7 \mathrm{~s}$, Fig. 5, Case 5). In contrast to catalytic combustion applications with high hydrogen contents in the fuel stream [27], the amount of $\mathrm{H}_{2}$ in the cases considered herein is not large enough to lead to front-end microreactor ignition. As evidenced from Fig. 5, FeCr alloy microreactors dissipate heat much faster via heat conduction through their walls than cordierite ones (due to their higher thermal conductivity), leading to broadly distributed reaction zones. This in turn hinders fast methane catalytic lightoff, leading to the higher $t_{\text {ig }}$ and $t_{\text {st }}$ times presented in Table 1. On the other hand, the steady-state temperatures are lower for the $\mathrm{FeCr}$ alloy material, suggesting that the material choice is a compromise between reactor thermal management issues and demand for fast light-off.

\subsection{Effect of hydrogen addition on the catalytic microreactor start-up process}

In the previous sections, the positive effect of hydrogen addition in the methane/air stream has been established regarding the subsequent reduction in characteristic ignition and steady-state times compared to pure methane/air cases, for all operating

Fig. 5 Channel wall streamwise temperature profiles during the start-up phase for Cases 5 (top graph) and 10 (bottom graph) at various time instances, including ignition (ign) and steady state (st)

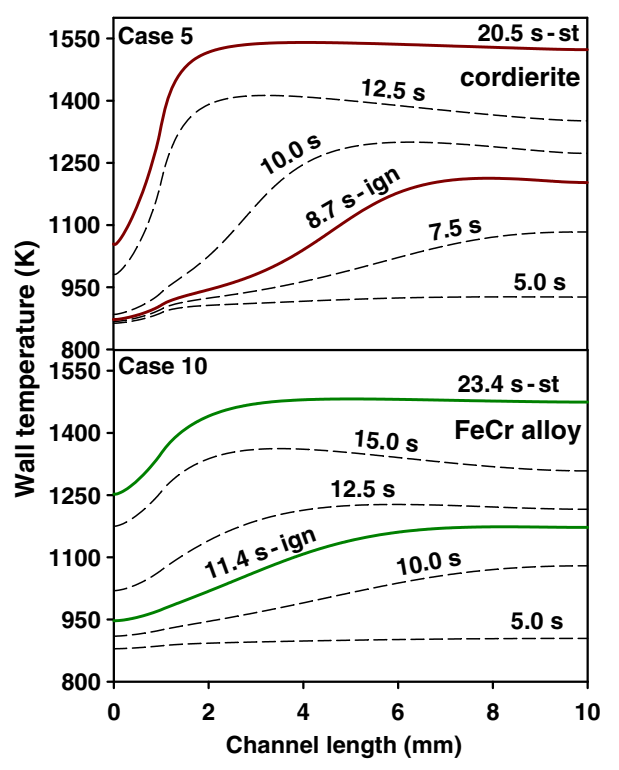

Springer 
pressures and microreactor materials considered. In this section, the underlying physics behind the heterogeneous combustion of $\mathrm{CH}_{4} / \mathrm{H}_{2}$ blends in catalytic microreactors will be investigated. Moreover, it will be clarified whether the promotion of catalytic combustion in microreactors with the addition of hydrogen is a thermal or a chemical effect.

Catalytic reaction rates for $\mathrm{CH}_{4}$ and $\mathrm{H}_{2}$ fuels are presented in Fig. 6 for Case 5 in Table 1, at two time instances before ignition and at the ignition and steady-state times. Substantial differences are evident in the reaction rate progress of the two fuels throughout the heat-up process. Since the microreactor wall temperature is initially set at $T_{W}=850 \mathrm{~K}$ (well-above the ignition temperature of $\mathrm{H}_{2}$ on platinum), the reaction rate of hydrogen peaks already at $t=0.0 \mathrm{~s}$ and $x=1 \mathrm{~mm}$ (the beginning of the catalytic section) and is fully consumed within the first half of the reactor. Methane on the other hand retains a low reaction rate in the early pre-ignition phase, only surpassing that of hydrogen close to the ignition time. After light-off and until steady state is reached, hydrogen exothermicity has a minor contribution to the heat generated from catalytic reactions in the microreactor, in contrast to the pre-ignition phase where heat is primarily generated from hydrogen conversion

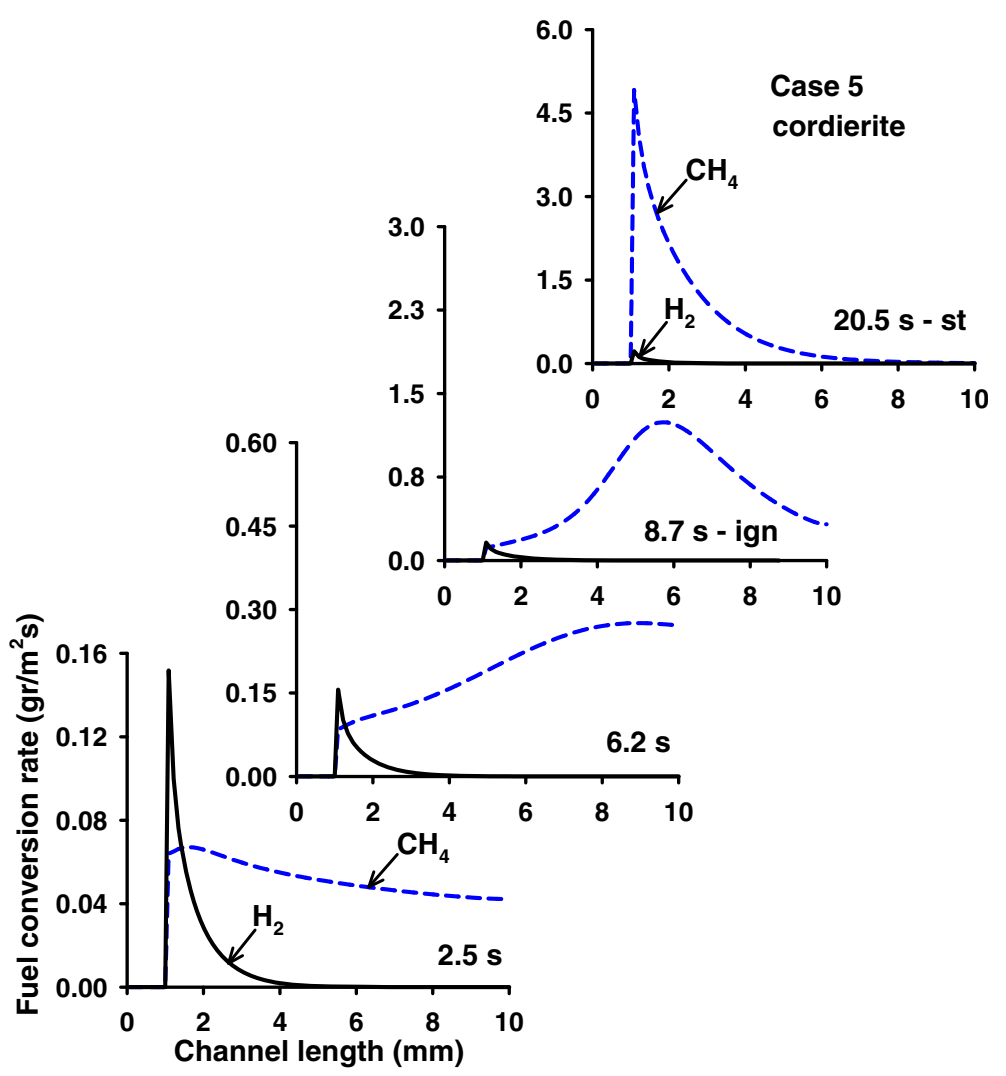

Fig. 6 Hydrogen (solid lines) and methane (dashed lines) catalytic conversion rates along the microreactor during the start-up phase for Case 5 at four time instances: ignition (ign), steady state (st) and two pre-ignition time instances 
on the channel wall surface. From Fig. 6 it is clear that, during hydrogen-assisted catalytic microreactor start-up, hydrogen has a strong thermal effect on the preignition process, at least for the present high inlet temperatures. With all of the $\mathrm{H}_{2}$ fuel being fully consumed already at early times, hydrogen complements the heat generated from the weakly-reacting methane fuel.

The chemical impact of $\mathrm{H}_{2}$ in microreactor start-up is assessed next. Figure 7 provides the wall temperature profiles and surface coverages for Case 1 ( $p=1$ bar, $\left.90 \% \mathrm{CH}_{4}-10 \% \mathrm{H}_{2}\right)$ at $t_{\text {ig }}$ and at the corresponding ignition time for the same case computed with $100 \% \mathrm{CH}_{4}$ in the fuel stream. It is evident that Case $1\left(\mathrm{CH}_{4} / \mathrm{H}_{2}\right.$ blend) has an overall higher wall temperature during ignition, with a subsequent lower $\mathrm{O}(\mathrm{s})$ coverage which promotes $\mathrm{CH}_{4}$ conversion by the associated higher surface availability of free $\mathrm{Pt}(\mathrm{s})$ sites. Moreover, hydrogen-containing surface species have higher surface concentrations for Case 1 (e.g. H(s) coverage, bottom panel of Fig. 7), particularly in the microreactor section preceding the catalytic reaction front which propagates towards the front-end (indicated by the high-temperature region, at $x>6 \mathrm{~mm}$, where $T_{\mathrm{w}}>1100 \mathrm{~K}$ ). Carbon-containing surface species on the other hand maintain similar levels as with the pure methane case. In order to investigate whether the addition of hydrogen in the fuel stream has a chemical impact

Fig. 7 Wall temperature profiles (top graph) and surface coverages (middle and bottom graphs) at ignition $\left(t_{\text {ig }}\right)$ for Case 1 (solid lines) and for the corresponding case with $100 \% \mathrm{CH}_{4}$ in the fuel stream (dashed lines). Temperature profiles and surface coverage are provided for the catalytically coated section $x \geq 1 \mathrm{~mm}$. Cordierite wall material

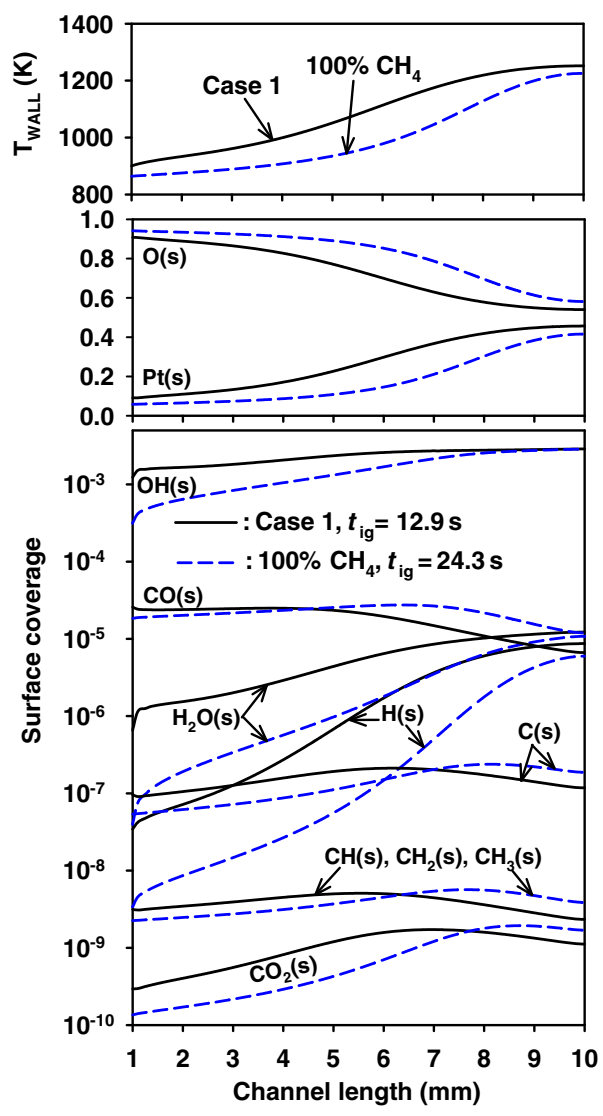


in the catalytic processes leading to microreactor light-off, a numerical experiment was conducted, in which the initial $10 \%$ of hydrogen by volume in the fuel stream was replaced by a fictitious species ${ }^{*} \mathrm{H}_{2}$ which had the same physicochemical and thermodynamic properties as $\mathrm{H}_{2}$ but a separate surface reaction pathway, leading to $\mathrm{H}_{2} \mathrm{O}$ as the final combustion product. Additional fictitious surface species (retaining the same physicochemical properties as the original species, but participating only in the prescribed reactions) were introduced for this separate reaction set, effectively adding the following surface reactions and species in the original detailed catalytic reaction mechanism:

$$
\begin{gathered}
{ }^{*} \mathrm{H}_{2}+2 \mathrm{Pt}(\mathrm{s}) \Rightarrow 2 * \mathrm{H}(\mathrm{s}), 2 * \mathrm{H}(\mathrm{s}) \Rightarrow{ }^{*} \mathrm{H}_{2}+2 \mathrm{Pt}(\mathrm{s}) \\
{ }^{*} \mathrm{H}(\mathrm{s})+\mathrm{O}(\mathrm{s})={ }^{*} \mathrm{OH}(\mathrm{s})+\mathrm{Pt}(\mathrm{s}) \\
{ }^{*} \mathrm{H}(\mathrm{s})+{ }^{*} \mathrm{OH}(\mathrm{s})={ }^{*} \mathrm{H}_{2} \mathrm{O}(\mathrm{s})+\mathrm{Pt}(\mathrm{s}),{ }^{*} \mathrm{OH}(\mathrm{s})+{ }^{*} \mathrm{OH}(\mathrm{s})={ }^{*} \mathrm{H}_{2} \mathrm{O}(\mathrm{s})+\mathrm{O}(\mathrm{s}), \\
{ }^{*} \mathrm{H}_{2} \mathrm{O}(\mathrm{s}) \Rightarrow \mathrm{H}_{2} \mathrm{O}+\mathrm{Pt}(\mathrm{s})
\end{gathered}
$$

Cases 1 to 10 were recomputed with the additional reaction set containing the fictitious hydrogen and surface species, yielding the same $t_{\mathrm{ig}}$ and $t_{\mathrm{st}}$ times as the ones presented in Table 1, thus exemplifying the absence of any chemical coupling between the catalytic reaction pathways of methane and hydrogen, at least for the conditions of this work. It should be noted that this is also due to the particularly low volumetric percentage of $\mathrm{H}_{2}$ in the total fuel/air flow $(\sim 0.4 \%)$ used in all the aforementioned computations. On the other hand, in cases of hydrogen and carbon monoxide mixtures whereby the former fuel constitutes a significant portion of the volumetric flow rate (such as in lean catalytic syngas combustion), hydrogen chemistry can play a significant chemical role in the start-up process [27, 28].

\subsection{Cumulative microreactor emissions}

Of particular interest in microburners intended for portable power generation applications is the emissions during their operation. During the start-up process, pollutants such as unburned hydrocarbons or $\mathrm{CO}$ can exit the microreactor with a direct impact on combustion efficiency and deterioration of the ambient air quality. In Fig. 8, the cumulative emissions, computed until steady state is reached, of unburned fuel (namely methane) are presented for Cases 1 to 5 (cordierite microreactor), and compared with the cumulative emissions of the corresponding microreactors operating with pure $\mathrm{CH}_{4}$ instead of $\mathrm{CH}_{4} / \mathrm{H}_{2}$ blends. Since most of the unburned fuel emissions occur in the pre-ignition phase of the start-up process, it is expected that the cumulative emissions will follow the same trend as the computed $t_{\text {ig }}$ times with respect to operating pressure. It is evident from Fig. 8 that the use of fuel mixtures of $90 \% \mathrm{CH}_{4}-10 \% \mathrm{H}_{2}$ exhibits reduced cumulative emissions of unburned methane, mainly due to the significantly shorter times required for microreactor ignition. Characteristically, a microreactor operating with the $\mathrm{CH}_{4} / \mathrm{H}_{2}$ fuel blend at 1 bar has fewer cumulative emissions than a microreactor operating with pure $\mathrm{CH}_{4}$ fuel at 5 bar. Hydrogen emissions are practically non-existent for Cases 1 to 5 , since complete hydrogen conversion is achieved at all time instances of the heat-up 
Fig. 8 Cumulative microreactor emissions of unburned $\mathrm{CH}_{4}$ versus pressure for Cases 1 to 5 (dashed line) and the corresponding cases computed for pure methane in the fuel stream (solid line)

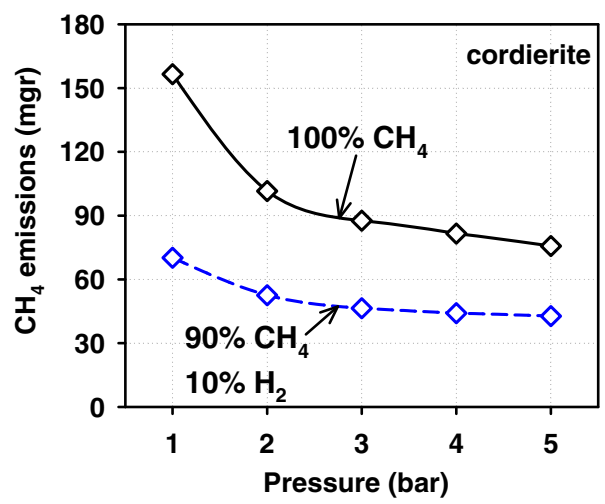

process. It should be noted that for a quantitatively correct assessment of microreactor emissions, detailed hetero-/homogeneous chemistry should be employed in the computations.

\subsection{Impact of gas-phase chemistry}

Gas-phase reactions are usually neglected in numerical simulations of catalytic microreactors. In recent numerical investigations, however, the effect of gas-phase reactions on the steady-state and transient behavior of methane-fueled catalytic microreactors has been demonstrated [7, 12]. In the present work, Cases 1, 5, 6 and 10 were recomputed with full hetero-/homogeneous chemistry and are presented as Cases 11, 12, 13 and 14, with their corresponding $t_{\text {ig }}$ and $t_{\text {st }}$ times provided in Table 1. In Fig. 9, 2-D distributions are given for methane, hydrogen and $\mathrm{OH}$ radical mass fractions for Case 12. Gas-phase chemistry affects ignition and steady-state times by contributing to the heat generation inside the channel and altering the spatial extend of the reaction zone over which fuel is consumed. For both pressures of $p=1$ and 5 bar and for both cordierite and $\mathrm{FeCr}$ alloy materials, gas-phase reactions have a

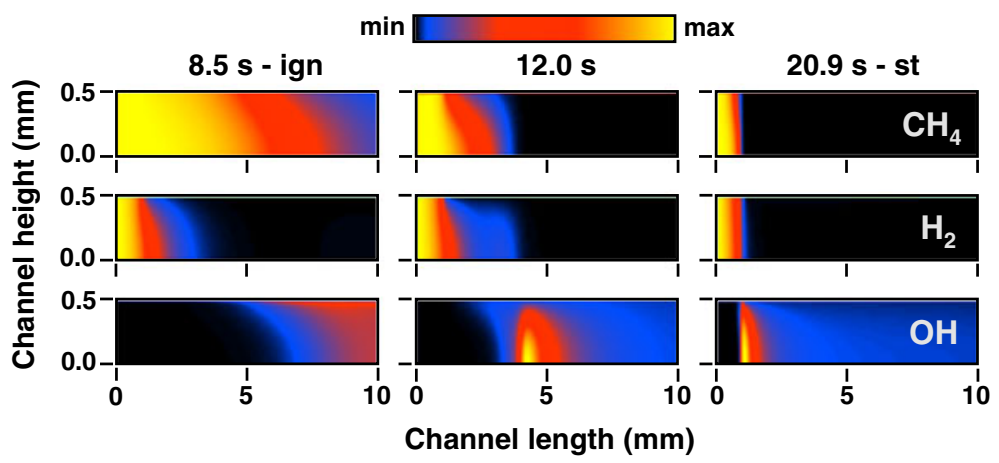

Fig. 9 Two-dimensional distributions of methane, hydrogen and $\mathrm{OH}$ radical mass fractions for Case 12 at three time instances, including ignition (ign) and steady state (st). The color bar defines minimum and maximum values. $\mathrm{CH}_{4}: 0.0$ to $0.0205 ; \mathrm{H}_{2}: 0.0$ to $2.8 \times 10^{-4}$. $\mathrm{OH}$ radical: minimum 0.0 and maximum $7.8 \times 10^{-7}$ for $t=8.5 \mathrm{~s}, 1.01 \times 10^{-4}$ for $t=12.0 \mathrm{~s}$, and $7.08 \times 10^{-4}$ for $t=20.9 \mathrm{~s}$ 
similar impact on the computed ignition and steady-state times. Gaseous chemistry contributes towards a faster microreactor ignition due to the weak exothermicity occurring in the gas phase. After ignition, however, and once the main reaction zone of fuel consumption is shifted from the catalytic wall to the gaseous domain (evidenced by the high $\mathrm{OH}$ radical concentrations, see Fig. 9 at $t=12.0 \mathrm{~s}$ ), gaseous chemistry elongates the time required for steady state due to the slower transfer of heat from the gas phase towards the microreactor wall (as opposed to the faster heat conduction in the solid wall). For the particular case of $\mathrm{CH}_{4} / \mathrm{H}_{2}$ combustion in catalytic microreactors, it is evidenced from Fig. 9 that full $\mathrm{H}_{2}$ consumption is already completed much earlier inside the microreactor compared to $\mathrm{CH}_{4}$, at least until $t_{\text {ig }}$. The extended reaction zone of $\mathrm{H}_{2}$, evident at $t=12.0 \mathrm{~s}$ in Fig. 9, is not due to fuel breakthrough, but due to the gas-phase production of $\mathrm{H}_{2}$ as an intermediate species from the now-vigorous $\mathrm{CH}_{4}$ gaseous combustion. Once steady state is achieved, the catalytic microreactor essentially operates as a gas-phase microcombustor (see Fig. 9, $t=20.9 \mathrm{~s})$.

\section{Conclusions}

The hydrogen-assisted start-up of methane-fueled, catalytic, channel-flow microreactors has been investigated numerically with a transient code that included full 2-D elliptic flow description, detailed hetero-/homogeneous chemistry, and all relevant heat transfer mechanisms. Parametric studies have been carried out to identify the effect of operating pressure and solid material properties on the transient processes leading to microreactor ignition and subsequent attainment of steady state. Direct comparisons were made with computations of microreactors operating with pure methane fuel. The following are the key conclusions of this study.

1. Hydrogen-assisted catalytic combustion significantly reduces the required times for light-off and attainment of steady state in methane-fueled catalytic microreactors. A fuel blend of $90 \% \mathrm{CH}_{4}-10 \% \mathrm{H}_{2}$ with a global equivalence ratio $\varphi=0.37$ achieved shorter ignition and steady-state times by $\sim 47 \%$ and $\sim 33 \%$ respectively compared to a fuel/air stream of pure $\mathrm{CH}_{4}$ with a global equivalence of $\varphi=0.40$, for a pressure of $p=1$ bar and a microreactor wall made of cordierite material. As the operating pressure increased, the benefit of employing hydrogen-assisted combustion was attenuated, due to the rising catalytic reactivity of methane.

2. Both $\mathrm{FeCr}$ alloy and cordierite catalytic microreactors exhibited shorter ignition and steady-state times with hydrogen-assisted catalytic combustion, compared to pure methane catalytic combustion. Cordierite microreactors benefited more due to their localized reaction zones which promoted faster light-off.

3. Hydrogen predominantly had a thermal impact on the start-up behavior of catalytic microreactors fueled with $\mathrm{CH}_{4} / \mathrm{H}_{2}$ blends, by providing significant exothermicity during the early times of the heat-up process. Due to the overall low volumetric percentage of hydrogen in the $90 \% \mathrm{CH}_{4}-10 \% \mathrm{H}_{2}$ fuel blends and the initially high microreactor inlet and wall temperatures, there was no chemical interaction between the catalytic reaction pathways of methane and hydrogen. 
4. Fuel blends of $\mathrm{CH}_{4} / \mathrm{H}_{2}$ had substantially lower cumulative emissions of unburned methane, for all pressures investigated. Due to the complete hydrogen consumption even at the early heat-up stages, no hydrogen breakthrough was evident.

5. Gas-phase chemistry for hydrogen-assisted methane combustion in catalytic microreactors had a similar impact as in pure methane-fueled catalytic microreactors, namely it reduced the ignition times and elongated the steady-state times.

Acknowledgements Support was provided by Paul Scherrer Institute (PSI) and the Swiss Competence Center for Energy and Mobility (CCEM).

\section{References}

1. Fernandez-Pello, A.C.: Micropower generation using combustion: issues and approaches. Proc. Comb. Instit. 29, 883-899 (2002)

2. Gomez, A., Berry, J.J., Roychoudhury, S., Coriton, B., Huth, J.: From jet fuel to electric power using a mesoscale, efficient Stirling cycle. Proc. Combust. Inst. 31, 3251-3259 (2007)

3. Karim, A.M., Federici, J.A., Vlachos, D.G.: Portable power production from methanol in an integrated thermoelectric/microreactor system. J. Power Sources 179, 113-120 (2008)

4. Ahn, J.M., Eastwood, C., Sitzki, L., Ronney, P.D.: Gas-phase and catalytic combustion in heatrecirculating burners. Proc. Combust. Inst. 30, 2463-2472 (2005)

5. Kaisare, N.S., Deshmukh, S.R., Vlachos, D.G.: Stability and performance of catalytic microreactors: simulations of propane catalytic combustion on Pt. Chem. Eng. Sci. 63, 1098-1116 (2008)

6. Maruta, K., Takeda, K., Ahn, J., Borer, K., Sitzki, L., Ronney, P.D., Deutschmann, O.: Extinction limits of catalytic combustion in microchannels. Proc. Combust. Inst. 29, 957-963 (2002)

7. Karagiannidis, S., Mantzaras, J., Jackson, G., Boulouchos, K.: Hetero-/homogeneous combustion and stability maps in methane-fueled catalytic microreactors. Proc. Combust. Inst. 31, 3309-3317 (2007)

8. Pizza, G., Mantzaras, J., Frouzakis, C.E., Tomboulides, A.G., Boulouchos, K.: Suppression of combustion instabilities of premixed hydrogen/air flames in microchannels using heterogeneous reactions. Proc. Combust. Inst. 32, 3051-3058 (2009)

9. Kaisare, N.S., Stefanidis, G.D., Vlachos, D.G.: Comparison of ignition strategies for catalytic microburners. Proc. Combust. Inst. 32, 3027-3034 (2009)

10. Tischer, S., Correa, C., Deutschmann, O.: Transient three-dimensional simulation of a catalytic combustion monolith using detailed models for heterogeneous and homogeneous reactions and transport phenomena. Catal. Today 69, 57-62 (2001)

11. Schneider, A., Mantzaras, J., Eriksson, S.: Ignition and extinction in catalytic partial oxidation of methane-oxygen mixtures with large $\mathrm{H}_{2} \mathrm{O}$ and $\mathrm{CO}_{2}$ dilution. Combust. Sci. Technol. 180, 89-126 (2008)

12. Karagiannidis, S., Mantzaras, J.: Numerical investigation on the start-up of methane-fueled catalytic microreactors. Combust. Flame 157, 1400-1413 (2010)

13. Schneider, B., Karagiannidis, S., Bruderer, M., Dyntar, D., Zwyssig, C., Guangchun, Q., Diener, M., Boulouchos, K., Abhari, R.S., Guzzella, L., Kolar, J.W.: Ultra-high-energy-density converter for portable power. Power-MEMS 2005, November 28-30, Tokyo, Japan (2005)

14. Isomura, K., Murayama, M., Teramoto, S., Hikichi, K., Endo, Y., Togo, S., Tanaka, S.: Experimental verification of the feasibility of a $100 \mathrm{~W}$ class micro-scale gas turbine at an impeller diameter of $10 \mathrm{~mm}$. J. Micromechanics Microengineering 16, 254-261 (2006)

15. Peirs, J., Waumans, T., Vleugels, P., Al-Bender, F.T.S., Verstraete, T., Stevens, S., D'hulst, R., Verstraete, D., Fiorini, P., Van der Braembussche, R., Driesen, J., Puers, R., Hendrick, P., Baelmans, M., Reynaerts, D.: Micropower generation with microgasturbines: a challenge. J. Mech. Eng. Sci. 221, 489-500 (2007)

16. Dogwiler, U., Benz, P., Mantzaras, J.: Two-dimensional modelling for catalytically stabilized combustion of a lean methane-air mixture with elementary homogeneous and heterogeneous chemical reactions. Combust. Flame 116, 243-258 (1999)

17. Siegel, R., Howell, J.R.: Thermal Radiation Heat Transfer, p. 271. Hemisphere, New York (1981)

18. Deutschmann, O., Maier, L.I., Riedel, U., Stroemman, A.H., Dibble, R.W.: Hydrogen assisted catalytic combustion of methane on platinum. Catal. Today 59, 141-150 (2000) 
19. Warnatz, J., Dibble, R.W., Maas, U.: Combustion, Physical and Chemical Fundamentals, Modeling and Simulation. Springer, New York (1996)

20. Reinke, M., Mantzaras, J., Schaeren, R., Bombach, R., Inauen, A., Schenker, S.: High-pressure catalytic combustion of methane over platinum: in situ experiments and detailed numerical predictions. Combust. Flame 136, 217-240 (2004)

21. Reinke, M., Mantzaras, J., Bombach, R., Schenker, S., Inauen, A.: Gas phase chemistry in catalytic combustion of methane/air mixtures over platinum at pressures of 1 bar to 16 bar. Combust. Flame 141, 448-468 (2005)

22. Kee, R.J., Dixon-Lewis, G., Warnatz, J., Coltrin, M.E., Miller, J.A.: A Fortran computer code package for the evaluation of gas-phase multicomponent transport properties. In: Sandia National Laboratories, Report No. SAND86-8246 (1996)

23. Coltrin, M.E., Kee, R.J., Rupley, F.M.: Surface Chemkin: a Fortran package for analyzing heterogeneous chemical kinetics at the solid surface-gas phase interface. In: Sandia National Laboratories, Report No. SAND90-8003 (1996)

24. Kee, R.J., Rupley, F.M., Miller, J.A.: Chemkin II: a Fortran chemical kinetics package for the analysis of gas-phase chemical kinetics. In: Sandia National Laboratories, Report No. SAND898009 (1996)

25. Lutz, A.E., Kee, R.J., Miller, J.A.: SENKIN: a Fortran program for predicting homogeneous gas phase chemical kinetics with sensitivity analysis. In: Sandia National Laboratories, Report No. SAND87-8248 (1996)

26. Karagiannidis, S., Marketos, K., Mantzaras, J., Schaeren, R., Boulouchos, K.: Experimental and numerical investigation of a propane-fueled, catalytic mesoscale combustor. Catal. Today 155, $108-115$ (2010)

27. Mantzaras, J.: Catalytic combustion of syngas. Combust. Sci. Technol. 180, 1137-1168 (2008)

28. Ghermay, Y., Mantzaras, J., Bombach, R.: Experimental and numerical investigation of hetero-/ homogeneous combustion of $\mathrm{CO} / \mathrm{H}_{2} / \mathrm{O}_{2} / \mathrm{N}_{2}$ mixtures over platinum at pressures up to 5 bar. Proc. Combust. Inst. 33, 1827-1835 (2011) 